\title{
Os paradoxos do acolhimento em Minas no século XIX de acordo com a literatura de viagem: hospitalidade e hostilidade ${ }^{1}$
}

The paradoxes of host at Minas in the 19th century according to the travel literature: hospitality and hostility Las paradojas del acogimiento en Minas en el siglo XIX de acuerdo con la literatura de viaje: hospitalidad y hostilidad http://dx.doi.org/10.18472/cvt.18n3.2018.1359

Leandro Benedini Brusadin 〈leandrobrusa@hotmail.com > Universidade Federal de Ouro Preto (Ufop), Ouro Preto, MG, Brasil

1 Artigo fruto de Pesquisa de Pós-Doutorado realizado na Escola de Artes, Ciências e Humanidades da Universidade de São Paulo com recursos tipo custeio do CNPq.

CRONOLOGIA DO PROCESSO EDITORIAL

Recebimento do artigo: 10-out-2016

Aceite: $28-m a i-2018$

FORMATO PARA CITAÇÃO DESTE ARTIGO

BRUSADIN, L. B. Os Paradoxos do Acolhimento em Minas no Século XIX de acordo com a Literatura de Viagem: hospitalidade e hostilidade. Caderno Virtual de Turismo. Rio de Janeiro, v. 18, n. 3, p. 108-122, dez. 2018.

REALIZAÇÃO

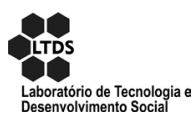

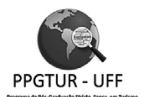

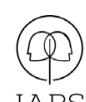

APOIO INSTITUCIONAL

EDIÇÃO

PATROCÍNIO

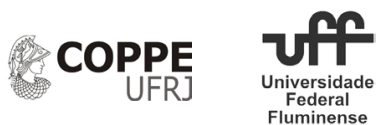

EDITORค

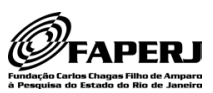




\section{RESUMO}

Este estudo, baseado na teoria da dádiva de Mauss (2008), posiciona como determinadas sociedades trocavam entre si e com os que eram considerados forasteiros. A hospitalidade pode ser inserida nesse contexto, ao ser definida como diversas formas e interpretações do ato do acolhimento humano, na relação de trocas com o outro em diferentes tempos e espaços. O objetivo deste trabalho é refletir sobre as práticas de acolhimento no Brasil, no século XIX, especificamente em Minas Gerais, sob a perspectiva dos viajantes naturalistas estrangeiros. A metodologia utilizada consiste na análise de fontes primárias referentes aos relatos presentes na Literatura de Viagem. Os viajantes estrangeiros registraram, sob um olhar eurocêntrico e de forma paradoxal, o processo de afetividade e alteridade em espaços distintos da hospitalidade, tais como no domínio comercial (hospedarias), no ambiente doméstico (casas e fazendas) e nos espaços públicos (vilas e cidades). Conclui-se que a sociedade mineira oitocentista ofereceu dádivas simbólicas aos viajantes estrangeiros em um processo de trocas assimétricas entre anfitriões e hóspedes com relações de hospitalidade e hostilidade.

Palavras chave: Acolhimento. Viajantes naturalistas. Minas Gerais. Hospitalidade. Hostilidade.

\section{ABSTRACT}

This study is based on the theory of gift from Mauss (2008) explain how some societys exchange with each other and with who were considered outsiders. The hospitality can be inserted in this context, to be conceived as various forms and interpretations of the human act of host, in relation of exchange with the other in different times and spaces. The goal of this paper is to think over on practices of host in Brazil in the 19th century, specifically in the State of Minas Gerais, from the perspective of the foreign naturalists travelers. The methodology used consists in the analysis of primary sources of the reports being at the Travel Literature. Foreign travelers registered, under a eurocentric and paradoxical perspective, the process of affectivity and otherness in distinct spaces, such as, in the business domain (hostels), in the domestic place (homes and farms) and in the public locals (towns and cities). It is concluded that the mineira society of the 19th century offered symbolic gifts to foreign travellers on affective involvement in an asymmetric exchange process between hosts and guests with hospitality and hostility.

Keywords: Host. Travellers, naturalists. Minas Gerais. Hospitality. Hostility.

\section{RESUMEN}

Este estudio basado en la teoría de la dádiva de Mauss (2008) explica como algunas sociedades actúan entre sí y con aquellos que eran considerados a extranjeros. La hospitalidad puede ser insertada en este contexto, pues estabelecela en variadas formas e interpretaciones del acogimiento humano, en la relación con el otro en distintos espacios y tiempos. El objetivo de esta investigación es reflexionar sobre las prácticas del acogimiento en Brasil en el siglo XIX, específicamente en la Provincia de Minas Gerais, sob la perspectiva de los viajeros naturalistas extranjeros. La metodología utilizada consiste en las análisis de fuentes primarias de la Literatura de Viajes. Los viajeros extranjeros registraran, desde su perspectiva eurocéntrica y de forma paradójica, el proceso de afectividad y alteridad en distintos espacios de hospitalidad, como en lo domínio comercial (albergues), en el entorno doméstico (hogares y haciendas) y en los espacios públicos (ciudades y pueblos). Se concluye que la sociedad minera del siglo XIX ofreció dádivas simbólicas a los viajeros extranjeros de forma afectiva en un proceso de intercambios assimétricos entre anfitriones y huéspedes con relaciones de hospitalidad y hostilidade.

Palavras clave: Acogimiento. Viajeros naturalistas. Minas Gerais. Hospitalidad. Hostilidad. 


\section{INTRODUÇÃO}

O pressuposto teórico deste trabalho parte do princípio que a superação de uma boa parte dos impasses que embaraçaram as ciências sociais, os debates da filosofia moral e a própria vida cultural passa pela exploração metódica das descobertas de Mauss (2008), contida na obra Ensaio sobre a Dádiva publicada originalmente entre os anos de 1923 e 1924. A tríplice ação relacionada pelo autor denominada "dar, receber e retribuir", enquanto fenômeno social total, pode constituir o universo antropológico sobre o qual foram construídas as sociedades antigas e que ainda contribui com a análise da cultura social de outras épocas. Mauss (2008, p. 217) entende que estudos desse tipo permitem "entrever, medir e ponderar os diversos motivos estéticos, morais, religiosos, econômicos e os diversos factores materiais e demográficos cujo conjunto funda a sociedade".

Sob a óptica da dádiva, a vida material e espiritual funciona sob uma forma de troca desinteressada e obrigatória ao mesmo tempo. Mauss (2008, p. 106) analisa que essa obrigação exprime-se de maneira mítica, imaginária, simbólica e coletiva, assumindo o aspecto do interesse ligado às coisas trocadas: "estas não estão nunca completamente desligadas aos seus agentes de troca; a comunhão e a aliança que elas estabelecem são relativamente indissolúveis". O social surge, assim, sob condições particulares de doação, confiança e solidariedade que não são explicáveis nem pela ótica do interesse individual, nem da burocracia estatal, mas sim, pelo paradoxo do dom. Desse modo, o termo paradoxal presente neste estudo possui o intuito de romper com dicotomias sociais por vezes entendidas ora como fruto de uma ação planificadora do Estado, ora movidas espontaneamente pelo mercado, ambas inseridas em contextos unilaterais da sociedade.

Pressupõe-se, neste artigo, que essa relação paradoxal se fez presente nas práticas de acolhimento realizadas entre os hóspedes viajantes naturalistas e os anfitriões brasileiros no século XIX. Considera-se que, por mais que houvesse o interesse econômico e mercantil de um com o outro, ocorreram práticas de sociabilidade que significaram atos de hospitalidade entre práticas de alteridade presentes nesse processo. Diante desse pressuposto, insere-se a importância de analisar as relações entre os viajantes estrangeiros e o povo mineiro no século XIX sob o caráter simbólico das coisas trocadas, fundamentalmente no que tange à hospitalidade e à hostilidade. Tais contrapontos foram relatados por diversas vezes nos diários de viagem entre os espaços de acolhida.

Entretanto, ressalvam-se as limitações dessa prerrogativa teórico-metodológica com as palavras de Lévi-Strauss (1988) quando detalha sua pesquisa etnográfica com várias comunidades da selva amazônica brasileira, de modo que diz, em seu diário de bordo, compreender a paixão e a loucura dos relatos de viagens, uma vez que por mais honesto que seja o narrador, não consegue descrever os fatos de forma autêntica. Ademais, o viajante do século XIX se colocava como alguém superior à realidade vivida e narrava os fatos com uma alteridade exacerbada.

Ainda assim, os viajantes têm sido convocados a dar conta de uma parte significativamente grande do nosso passado e de seu discurso sobre o "outro", em um contexto colonialista, não suficiente como um instrumento de dominação, pois toda representação se faz como veículo de expressão e manifestação de uma cultura (LEITE, 1996).

Os viajantes do século XIX também tinham um interesse pessoal de viajar ao Brasil que variava entre a ambição de estudos e pesquisas, aquisição financeira, vontade própria de diversão e lazer, além do exercício e pregação da fé religiosa. Obviamente que, para além dos interesses pessoais dos viajantes, 
existia a lógica institucional dos financiadores independentes e governamentais relacionada à exploração de recursos naturais, à conquista de mercados para os produtos industrializados, investimento de capitais e ao aumento da riqueza e da soberania nacional. Não obstante, havia o interesse do público leitor europeu dos diários de viagem, visto que o viajante se preocupava em estimular a curiosidade do leitor o qual divulgava e legitimava a relevância daquela obra.

Com a chegada de D. João VI ao Brasil, em 1808, o qual passou a ser sede administrativa do império português, iniciou-se a ruptura do antigo sistema colonial e o País abriu-se ao conhecimento do mundo. A partir daí os viajantes chegaram a Minas Gerais através do Rio de Janeiro em trajetos longos, médios ou curtos a depender do objetivo da viagem que, em comum, tinham o tom de registro histórico por um lado e, por outro, elaboravam uma imagem eurocêntrica, revelando interesses norteados em contextos de exploração colonial. De acordo com Torres (1980), houve no primeiro momento a influência exclusivista portuguesa (século XV ao XVIII), no segundo, a influência europeia permitida pela abertura dos portos, sobretudo da Inglaterra, devido à sua participação na transferência da Corte (século XIX) e, no terceiro momento, a influência norte-americana por sua inserção no sistema global (século XX).

Perante a esta proposta do estudo dos relatos dos viajantes, sob a prerrogativa do sistema da dádiva, vêse a problemática principal desse trabalho: como era interpretada a hospitalidade em Minas a partir dos relatos dos viajantes estrangeiros do século XIX sob a óptica da teoria da dádiva? As práticas simbólicas de doação, recepção e retribuição nos auxiliam a compreender as relações assimétricas ${ }^{2}$ de poder estabelecidas entre os estrangeiros europeus e o povo mineiro daquele período nos diferentes espaços.

\section{LITERATURA DE VIAGEM: DELIMITAÇÃO E RELATIVIZAÇÃO DAS FONTES HISTÓRICAS}

Antes de penetrar no conteúdo dos relatos dos viajantes é preciso relativizar que, naquele quadro social da realidade brasileira, o escritor viajante estrangeiro construiu no Brasil, durante o século XIX, uma representação a partir dos seus pressupostos, de suas categorias e de seus preconceitos. O viajante europeu adentrou, assim, no complexo jogo da alteridade cultural quando acaba por olhar não somente para o novo, mas também espelhando-se no outro, olha para si refletindo sobre si mesmo, fazendo emergir uma relação de trocas de hospitalidade e hostilidade com o povo que o acolhia.

O uso da literatura dos viajantes como fundamentos empíricos de explicações sociológicas, históricas, antropológicas etc., sem a sua devida relativização em relação ao colonialismo, ao racismo e ao etnocentrismo, acaba por efetivá-los, ou seja, reproduz, no interior de trabalhos que pretendem ser críticos, as ideias que tentam superar (LEITE, 1996, p. 230).

Diante dessa perspectiva histórica e etnográfica dos relatos dos viajantes, Augustin (2009, p. 10) assevera que "os estudos dos relatos dos viajantes permitem avaliar se seu conhecimento alimentou o imaginário brasileiro do mito fundador, da visão do paraíso, da natureza pura tropical ou até que ponto seus olhares contribuíram para diferenciar uma imagem estereotipada e dicotomizada".

20 termo assimétrico utilizado no texto refere-se à diferença de níveis da coisa dada e retribuída entre os protagonistas da relação de dádiva (GOTMAN, 2009). Dessa forma, não representa simetria ou equilíbrio de poder entre o viajante estrangeiro e o anfitrião brasileiro na sociedade daquele período (século XIX). 
Desse modo, identifica-se que o culto ao outro exerceu um verdadeiro fascínio entre os viajantes, reproduzido nessas publicações de viagem a lugares exóticos as quais circulavam entre os intelectuais na Europa. O significado simbólico das descrições de viagem revela uma necessidade por parte do viajante do século XIX de romper a diferença entre lugares e temas desconhecidos e entre valores culturais distintos. A preocupação e o interesse pela natureza e suas fontes de recursos fizeram com que muitos se tornassem naturalistas, porém, existia, ainda, uma abordagem geral sobre temas variados e exóticos, tais como o lazer, o comércio e a própria hospitalidade com a descrição de cenas da vida social cotidiana.

Fato é que o material escrito e iconográfico dos viajantes naturalistas estrangeiros do século XIX, no Brasil, tem servido como sustentação das mais diferentes teorias acerca dessa população, especialmente a de Minas Gerais. Tais viajantes e seus diários de viagem tornaram-se peça-chave na contextualização histórica e antropológica daquele período.

Os viajantes estrangeiros organizaram parte do material empírico e chegaram a observações tão argutas, mas tão expressamente enlevadas que, não por mera casualidade, firmaram os pilares para a construção imaginária da própria hospitalidade mineira. O processo de acolhida tinha para eles grande força sedutora, tornando-se capaz de criar espantos, alimentar emoções e de promover identificações. Arruda (1990, p. 22) diz que "a adesão mítica abriu as portas de entrada para um plano de vida superior e os homens julgaram encontrar o repositório da sua identidade". Para essa mesma autora, o gosto pelo ganho fácil e sem muito dispêndio de energia assustava bastante os viajantes, uma vez que para aqueles homens formados na ética do trabalho, tornara-se incompreensível o fato de ninguém querer ganhar dinheiro.

Os diários de viagens a Minas Gerais no século XIX, analisados em seu sentido etnográfico, literário e histórico, constituem-se textos de fronteira, reafirmados de dentro da experiência do ser estrangeiro. Importante ressalvar que cada viajante constrói o texto sistematizando fragmentos da experiência da viagem de outros, de suas vivências, expectativas e frustrações. Surgem daí infinitas possibilidades de representar que transformam a análise de tais diários em uma experiência de viagem de diversas armadilhas (LEITE, 1996).

Diante dos relatos dos viajantes, considera-se que as representações sobre o outro nasceram de um processo de comparação, classificação e ordenação das experiências das viagens. A produção científica sobre o Brasil daquele período, especialmente pelos viajantes estrangeiros, é fruto das exigências impostas pela expansão do capitalismo no sentido de revelar aos interesses europeus a potencialidade do País. De acordo com Augustin (2009), esse fato foi o principal gerador de um ciclo de viagens e expedições científicas que se estenderam por todo o século XIX.

Os dados acumulados por essas viagens se tornaram nacionais e internacionais mesmo que sujeitos aos discursos científicos e utilitaristas dos viajantes que se julgavam superiores diante dos demais. No século XIX, o olhar quantificador da economia pressupõe a percepção da natureza e das relações sociais de modo que tais fatos estão contidos nos diários de viagem na forma de estatística e na descrição numérica dos fenômenos. De qualquer forma, os textos dos viajantes estrangeiros textualizam seus olhares e as imagens percebidas, combinados com suas situações pessoais e acontecimentos internos brasileiros. A premissa teórica da hospitalidade, à luz da teoria da dádiva, permite compreender o processo de trocas estabelecidas entre os viajantes e os mineiros daquele período. 
Entretanto, de acordo com Brusadin e Panosso Netto (2016, p. 538) "la idea de hospitalidad no implica la inexistencia de hostilidad y no deja de lado las formas arbitrarias de dominación y manipulación”. Assim, importa, para este artigo, o olhar paradoxal contido nesses relatos em que tratam da natureza humana em sua dimensão material e imaterial, em um viés espiritual e simbólico do poder das coisas trocadas entre os viajantes que chegavam e os brasileiros que os recebiam de forma livre e obrigatória ao mesmo tempo.

\section{OS VIAJANTES NATURALISTAS E O ESPÍRITO DA HOSPITALIDADE EM MINAS: PARADOXOS DO PROCESSO DE ACOLHIMENTO}

Os relatos dos viajantes que vieram ao Brasil no século XIX perpassam análises paradoxais sobre o comportamento do brasileiro e do próprio viajante em suas perspectivas social, econômica e política. Nesse sentido, é possível revelar a visão controversa da sociedade europeia sobre esse povo e sobre si mesma. Por isso, a partir desse momento, nos pautamos nos relatos de alguns viajantes que estiveram em Minas, especificamente em Vila Rica, antiga capital da Província denominada posteriormente como Ouro Preto, os quais traçam o que se considerava fator de hospitalidade e hostilidade para o estrangeiro naquele período. Torna-se imprescindível analisar as fontes primárias que registram as dádivas trocadas em tais relações as quais foram expressas simbolicamente no trato com o outro.

Entre os relatos dos viajantes quanto à hospitalidade antiga em Minas, é comum encontrar orientações aos outros viajantes quanto ao que poderiam se deparar em terras brasileiras. Nesse sentido, situam-se os escritos de Pohl ${ }^{3}$ (1976, p. 103) o qual aconselhava aos demais visitantes: "devemos tolerar, por serem habitantes de um lugar pouco frequentado por viajantes, a curiosidade e uma certa importunação que ela origina". Caldcleugh $^{4}$ (1825, p. 203) comenta que "em Vila Rica um mulato entra cheio de cumprimentos e admira as minhas roupas finas. Pede mil perdões e se apresenta como alfaiate da Vila e quer copiar o modelo de minhas roupas". Ainda assim, $\operatorname{Mawe}^{5}$ (1978, p. 132) narra a sua acolhida ao dizer que "o administrador do Conde nos forneceu animais, a mim e ao meu companheiro, e o Senhor Lucas, o Juiz, teve a amabilidade de providenciar para tudo quanto ao necessário a nossa viagem”. Outro viajante, Wells ${ }^{6}$ (1886, p. 84-85) disse que "os negros eram excelentes anfitriões".

Nesse sentido, os viajantes Spix e Martius $(1981$, p. 189) dizem o seguinte ao se aproximarem de Vila Rica:

O acolhimento amável, verdadeiramente patriarcal que nos deram no alto da montanha solitária, numa quinta isolada, a Fazenda do Córrego dos Pinheiros, condizia com a nossa disposição de espírito. Parecia que aqui se estava acostumado à sociedade dos vizinhos, e cada qual, a quem o dono da fazenda tinha dado licença de descarregar, hospedava-se na fazenda, sem ser permitido pagar qualquer coisa a não ser o milho necessário às bestas cargueiras. Esse costume hospitaleiro e igual bondade encontra-se em grande parte de Minas.

\footnotetext{
30 mineralogista, botânico e médico Johann Emanuel Pohl era austríaco e viajou pelo Brasil entre 1817 e 1821 . Seus diários de viagem registram aspectos da história econômica e social brasileira (POHL, 1976).

40 naturalista Alexandre Caldcleugh era inglês e viajou pelo Brasil em 1821 e pretendeu um relato científico por mais que tenha privilegiado circunstâncias políticas (CALDCLEUGH, 1825).

50 comerciante John Mawe era inglês e viajou pelo Brasil entre 1809 e 1818. Registrou aspectos da Mineralogia e da Geologia, apesar de vir ao País visando o seu próprio enriquecimento (MAWE, 1978).

60 naturalista James Willian Wells era inglês e viajou pelo Brasil em 1885 relatando principalmente aspectos da economia e da geografia (WELLS, 1886).

70 zoólogo Johann Baptist Von Spix e o botânico Karl Friedric Philipp Von Martius são alemães e visitaram várias regiões do Brasil entre 1817 e 1820 para uma missão científica. Registraram aspectos da Geologia, Botânica, Zoologia, Climatologia, Etnologia, Música, Política e Economia (SPIX; MARTIUS, 1981).
} 
É possível observar que o tempo de permanência do viajante em Minas, mesmo quando curto, consolidava o vínculo afetivo entre visitante e anfitrião, desdobrando-se em diversos ritos de hospitalidade e hostilidade. Recebidos pelos fazendeiros e administradores das minas, os viajantes eram atendidos pelos escravos que serviam as casas, porém, os negros e as negras não foram registrados como pertencentes à entidade doméstica, típico de uma sociedade escravista e patriarcal.

Diante dos relatos da hospitalidade fornecida aos viajantes que passaram por Minas Gerais, no século XIX, todos destacaram a espiritualidade, a dança e a música como traços característicos da cultura dos negros africanos e seus descendentes. Por outro lado, a associação com ausência de racionalização do trabalho e com o trato das coisas públicas é frequente na literatura de viagem. É preciso levar em conta que os relatos dos viajantes não se mostram apenas contraditórios em si, mas reprodutores de controvérsias existentes na sociedade que retratam.

Desse modo, são raras as descrições imanentes de compreensão da riqueza cultural de um ritual, ou de uma dança ou de uma festa, já que predomina o horror causado pelo que os viajantes denominariam selvajaria. Tais viajantes são testemunhas dos mitos fundadores da nacionalidade brasileira, tais como, sagração da natureza, indistinção entre o público e o privado, enfraquecimento da lei, imagem de boa sociedade na qual os conflitos e as contradições são sinônimos da desordem e cultura senhorial que considera a elite como a mais nobre. Os viajantes trataram, assim, de mitos, de crenças, de representações, em suma, de discursos nos quais simbolizavam para eles próprios a hospitalidade daquela sociedade.

Durante sua estada em Vila Rica, outro viajante, Freyress ${ }^{8}$, encontrou dificuldades para fixar relações com as pessoas que ali viviam, pois "é necessário conhecer bem os costumes exteriores da vida, da religião, etc., para viver bem com a população" (ARRUDA, 1990, p. 84). Isso já identifica um dos paradoxos da hospitalidade mineira, posto que o pressuposto da afetividade não pressupunha, necessariamente, a abertura ao "outro", tal como no conceito explorado por Derrida (2004) em sua hospitalidade infinita. De qualquer forma, já era possível observar que os mineiros tinham no tratamento pessoal uma questão afetuosa de sua personalidade, formalizando uma tradição que seria a marca da sua hospitalidade.

O vínculo estabelecido com o lugar e com as pessoas era revestido por dois aspectos fundamentais: a "transitoriedade" marcada pelo fato de ser de fora podia significar o aumento ou a diminuição da confiança e a "indeterminação" que consistia na possibilidade de manter o vínculo com pessoas de várias posições sociais. A ambiguidade dessas relações aparece nitidamente nos textos dos viajantes forjados ao seu critério, de acordo com os limites da diferença com o outro. Outro exemplo dessa narrativa tem-se na percepção dos viajantes de que, além da procedência e da cor da população negra, que indicavam a inferioridade natural, o negro era diferente por seu trabalho e por sua (falta de) cultura. O escravo atraía o viajante pela sua capacidade de realizar o trabalho e por sua cultura desconhecida, tendo em vista que o estrangeiro se colocava como representação do senhor (LEITE, 1996).

É importante situar os diferentes tipos sociais daquela sociedade hierárquica. Durante todo o século XIX, a maioria dos viajantes que chegava a Minas se defrontava com o grande número de negros, escravos e libertos, em comparação com os brancos, entendidos exclusivamente como europeus, independente da procedência étnica. Os mulatos aparecem como um grupo derivado pela miscigenação, inclusive com índios.

80 viajante Georg Wilhelm Freyress era alemão e esteve no Brasil entre 1814 e 1815 e relatou aspectos da cultura brasileira e as características da natureza do País (LEITE, 1996). 
Apesar de os relatos narrarem o comportamento afetivo do povo mineiro, vê-se que a sociedade daquele período não se traduzia necessariamente por elementos pacificadores. A opressão foi relatada pelos viajantes como muito mais cruel em Minas, provocando a rebeldia que culminou na Inconfidência Mineira, fazendo emergir a figura de Tiradentes. O viajante Burton' $(1976$, p. 291) descreve esse movimento classificando-o como uma embrionária tentativa de estabelecer a república: "É evidente o caráter democrático da insurreição que o governo chamou de Conjuração ou Levante de Minas, e que hoje é conhecido popularmente como Inconfidência e tornou-se tão 'sagrado”'.

Nessa construção mitificada de Minas é comum encontramos o imaginário do drama de Tiradentes e a pluralidade regional integrada, já que sua unidade advém do fato de haver recolhido e guardado pedaços do Brasil. A construção mítica é atemporal, pois os movimentos do tempo - passado, presente e futuro - convivem harmonicamente, encontram-se mesclados e indiferenciados. Em Minas, essa construção "engendrou uma sociabilidade específica que se inclina à mitificação" (ARRUDA, 1990, p. 128). O termo mitificação se refere à construção de mitos que buscaram fornecer uma suposta coesão social da formação da identidade brasileira a partir de imaginários que representassem a cultura do povo mineiro e de sua identidade.

Ademais, o hibridismo cultural se entrelaçava na sociedade mineira, pois a relação entre senhores e escravos, brancos e negros, fazendas e vilas faria emergir questões sociais complexas que não se explicam somente pelas práticas de opressão étnico-racial ali exercidas. As relações entre os viajantes e o povo mineiro do século XIX traduzem, na prática, as problemáticas discutidas no trato com o outro em um processo de trocas realizadas que tiveram um cunho paradoxal, pois tal hibridismo não se fundou no caráter democrático no sentido étnico e social.

Identifica-se tal aspecto nos diários de viagem de Burton (1976, p. 307) ao relatar a sua estadia em Ouro Preto: "o ligeiro contato com a sociedade deixou-nos muitas impressões agradáveis, e custa-nos a compreender aqueles viajantes que se queixam de que 'não é o estilo das coisas a que estão acostumados"'. Entretanto, Burton (1976, p. 335) diz que outro viajante, Saint-Hilaire, se tornou quase um mineiro de modo que

sentiu falta de cordialidade quando saiu de Minas. Minha experiência foi ao contrário. O paulista, embora reservado, sente-se mais à vontade com os estrangeiros do que seu primo; este último pode ser descrito como acanhado. [...] Ambas as províncias são igualmente hospitaleiras, ambas não gostam de reservas excessivas.

Esse mesmo viajante diferencia a hospitalidade dos paulistas e dos mineiros no trato com o outro e descreve a seguinte situação:

\begin{abstract}
$\mathrm{Na}$ estrada, porém, o paulista tira o chapéu, dá um bom dia cordial e responde de boa vontade a todas as perguntas. O mineiro nos olha bem antes de tirar o chapéu, muitas vezes sua mão fica suspensa entre a sela e a cabeça, imaginando, infantilmente, se o estranho irá, ou não, corresponder ao cumprimento. Algumas vezes olhavam para mim de maneira hostil, as mulheres "fechavam a cara" e os homens davam uma resposta ríspida, que cortava toda a esperança de intercâmbio (BURTON, 1976, p. 335).
\end{abstract}

O fato de os mineiros supostamente preferirem ficar à toa, em vez de usufruir um lazer que lhes custou caro com o esforço do trabalho, também foi relatado pelos viajantes. Arruda (1990, p. 54) afirma que “os simples pares ócio-hospitalidade, ócio-paternalismo e ócio lazer são primorosos nesse sentido". A

90 orientalista Richard Francis Burton era inglês e viajou pelo Brasil no ano de 1868. 0 escritor relatou aspectos naturais e antropológicos da sociedade brasileira daquele período (BURTON, 1976). 
hospitalidade dispendida na atenção aos viajantes estrangeiros foi entendida como uma estranha forma de tempo ocioso gasto com o outro, já que os homens brancos não eram obrigados a tal.

Burton (1976) nos remete a outra questão paradoxal da antropologia social do mineiro. O viajante diz que o mineiro é um homem religioso, mas um católico displicente, entretanto possui certo horror de tudo aquilo que não é católico. Tem-se em vista que a presença barroca nas Minas teve conexões com o quadro de sociabilidade híbrida desenvolvido nas cidades da capitania. Em Vila Rica, no século XVIII, havia grande densidade populacional que possibilitou o surgimento de variadas atividades econômicas. A dramatização barroca amolda-se àquela sociedade que buscava ritualizar a necessidade de permanência das diferenças no todo em que a Igreja mineira tornara-se o instrumento de diferenciação de vários grupos. O apego ao passado e à família representava a identidade do mineiro porque as memórias significam a tentativa de recuperação no imaginário social da antiga posição econômica da família ou mesmo da fantasia social que se criou pelo ato de acolher o estrangeiro.

Apesar disso, é preciso considerar que as relações sociais em Minas se davam, naquele período, por meio de uma relação estritamente racial fruto de hierarquia imposta pelo Império e por uma sociedade eurocêntrica. Cada tipo físico tinha sua função no processo de acolhimento e, obviamente, cabia aos negros as funções desprestigiadas a fim de que os brancos pudessem expor sua forma de poder para os visitantes que eram recebidos tanto no meio rural quanto no meio urbano. A hospitalidade a estrangeiro era realizada a partir de uma hostilidade aos negros. Fato é que as relações de trocas estabelecidas naquela sociedade tinham os pressupostos de tais obrigações, todavia, exercia o culto pelo outro diante da alteridade situada em diversos gestos que estiveram presentes no ato material e espiritual de cada acolhida simbolizada em forma de dádivas enquanto exercício de poder.

A dádiva constituiu sistema de relações propriamente sociais enquanto práticas irredutíveis e das relações de interesse econômico ou de poder (MAUSS, 2008). Entretanto, a perspectiva fluída das relações sociais estabelecida entre os viajantes e o povo mineiro daquele período se entrelaça com a teoria da dádiva visto que "o dom é a alternativa da dialética do senhor ao escravo. Não se trata de dominar os outros, nem de ser dominado; nem de domesticar a natureza, nem de ser enganado por ela; mas de pertencer a um conjunto mais vasto, de restabelecer a ligação, de se tornar membro", assinala Godbout (1999, p. 313).

Assim, vê-se que a sociedade brasileira do século XIX representou simbolicamente atitudes paradoxais de dádiva as quais não se explicam isoladamente pela disputa de poder entre o europeu dominador e o brasileiro explorado, já que se deu, também, pela essência do espírito humano em trocar um com o outro enquanto sociedade. Veremos como isso ocorreu na lógica do acolher, essencialmente, entre o alimentar e o hospedar.

\section{AS PRÁTICAS DE HOSPEDAGENS E A ALIMENTAÇÃO EM MINAS NO SÉCULO XIX: HOSPITALIDADE E HOSTILIDADE}

Nos relatos de viagem pelas Minas do século XIX identificam-se as práticas de acolhimento representadas pela hospedagem e alimentação oferecidas, algumas vezes em formas de dádivas, essencialmente no que tange ao ambiente doméstico e público. 
Quanto à hospitalidade comercial, a maioria dos pousos estava somente preparados para oferecer uma refeição de feijão, farinha e carne seca ao viajante, além de milho para o seu animal. Com o decorrer dos anos, surgiram mais estalagens ou hospedarias as quais eram compostas de três ou quatro quartos de terra batida, teto sem forro, jiraus com colchão e travesseiros de palha de milho, quando não eram simples esteiras no chão.

Nesse intuito, Lashley (2015, p. 75) apresenta o vínculo entre a noção de hospitalidade comercial e o passado das religiões judaico-cristãs que "desenvolveram uma forte consciência da necessidade de oferecer hospitalidade e de dar alimento, bebida e hospedagem aos estrangeiros e necessitados" de forma distributiva. Nesses termos, Camargo (2004) se questiona: onde estaria o sacrifício na hospitalidade comercial e se esta traz consigo elementos do sistema do dom.

Em Minas, esse espaço de hospitalidade se dava nos pousos dos bandeirantes ou em pontos das paradas de tropas as quais foram responsáveis por fazer surgir as cidades. Nesses locais, diferentemente das fazendas, a acomodação era cobrada, sendo quatro vinténs por noite a cada viajante, de modo que os tropeiros dormiam em redes e preparavam sua própria refeição. Ainda assim, divertiam-se cantando e tocando violão, fato o qual esboça a sociabilidade fundada no apogeu do ouro e, posteriormente, na crise da mineração.

Ao viajar do Rio de Janeiro para Ouro Preto por 18 dias, o viajante $\operatorname{Bunbury}^{10}(1981$, p. 63) relata que "por toda a extensão desta estrada, contudo, achei os vendeiros, em geral, muito mais corteses do que daquela pela qual voltei para o Rio; e nunca me faltou comida". Mesmo assim, o viajante diz que leite e pão obtinham-se raras vezes e vinho quase nunca. Algumas hospedarias eram tão sujas e desconfortáveis que faziam com que os viajantes saíssem de madrugada, de modo que esse mesmo viajante recomendou que era necessário levar consigo sal, sabão, duas marmitas, um chifre para água e um guarda-chuva como objetos indispensáveis.

Para os viajantes, era difícil suportar as picadas de insetos de modo que Pohl (1976, p. 40) relata, em sua experiência, que "entrando a noite chegavam os verdadeiros mosquitos [...] que eu fiquei inteiramente inchado e como se sofresse de uma erupção cutânea”. Saint-Hilaire (1975, p. 73), ao tratar de sua passagem por Vila Rica, diz que "os estrangeiros nem sequer têm o recurso de aí encontrar uma hospedaria suportável".

É preciso levar em conta que o viajante acaba por fazer uma observação um tanto exagerada sobre a hospitalidade comercial, doméstica e pública dos mineiros daquele período tendo em vista o seu olhar eurocêntrico. No caso da alimentação, por exemplo, Saint-Hilaire (1975, p. 81) testemunha o seguinte: "os mineiros não costumam conversar quando comem. Devoram os alimentos com uma rapidez que, confesso, muitas vezes me desesperou [...]. Depois da refeição, os comensais se levantam, juntam as mãos, inclinam-se, rendem graças, fazem o sinal da cruz e, em seguida, saúdam-se reciprocamente". Esse mesmo viajante foi quem mostrou a cozinha como um espaço especificamente feminino.

As dádivas feitas na forma de comida no ambiente doméstico, realizadas por meio de convites para jantares, possuíam um papel de grande importância para obtenção de prestígio e para ostentação da suposta riqueza das famílias locais ao passo que serviam, ao mesmo tempo, para ofertar alimentação em abundância dos produtos locais para os viajantes estrangeiros.

100 naturalista Charles James Fox Bunbury era inglês e viajou pelo Brasil entre 1833 e 1835. Registrou aspectos da botânica e da mineralogia, além de apontar os costumes políticos do País (BUNBURY, 1981). 
Se dermos as coisas e as retribuirmos é porque nos damos e nos retribuímos respeitos - dizemos ainda mais delicadezas. Mas também que damos a nós mesmos aos darmos aos outros, e, se damos a nós mesmos, é porque devemos a nós mesmos - nós e o nosso bem - aos outros (MAUSS, 2008, p. 121).

Com tais intuitos, Pohl (1976, p. 386) foi recebido pelo Governador-Geral e foi convidado para almoçar aos domingos em sua casa em Ouro Preto. Após ser instalado em uma bela residência, a qual fora cedida a ele, afirma o seguinte:

Eu devia essa excelente acolhida à bondade e amizade do senhor von Eschwege, que ainda se encarregou pessoalmente de reorganizar a minha tropa com animais descansados, obter-me novos criados e atender às minhas necessidades durante a minha prolongada permanência nesta cidade.

Assim, a partir do relato do viajante europeu é possível analisar que as relações do "bem receber" das famílias na região das Minas no ambiente doméstico já eram uma tradição no século XIX, fato este vinculado a fatores religiosos, políticos e socioafetivos. Por isso, crê-se que os interesses utilitaristas não explicam esse processo de acolhida como um todo, pois a satisfação em receber dados hóspedes poderia representar, naquele período, tanto o desejo da convivência social quanto da exposição de um dado prestígio. Tem-se como exemplo o relato de Mawe (1978, p. 145) ao se despedir de um pouso fornecido e analisar a acolhida: "ao despedir-me do cavalheiresco velho, não pude conseguir que, por sua bondade, aceitasse alguma recompensa. Respondeu a meus agradecimentos assegurando-me que ficara muito contente com minha presença".

Mas é a comida mineira que expressa o arcabouço mais preciso das relações de alteridade entre os viajantes naturalistas e o povo mineiro. Os rituais essencialmente simbólicos estendem para além do ato material de alimentar-se. Nesse sentido, Saint-Hilaire $(1975$, p. 96$)$ relata sobre a experiência dos alimentos e seus sabores em Minas:

\footnotetext{
Galinha e porco são as carnes que se servem mais comumente em casa dos fazendeiros da Província de Minas Gerais. O feijão preto é indispensável na mesa do rico, e esse legume consiste quase na única iguaria do pobre. E a esse prato grosseiro ainda se acrescenta alguma coisa, é arroz, ou couve, ou outras ervas picadas [...] como não se conhece o fabrico da manteiga, é substituída pela gordura que escorre do toucinho que frita.
}

O estilo da cozinha mineira revela-se no complexo do milho, na carne de porco, no café e na aguardente de modo que o espaço da cozinha era um lugar importante para o mineiro que, passada a série de crises, alimentava-se bem e melhor do que a maioria dos brasileiros:

\footnotetext{
[...] nos grandes dias queria assentar-se com a família e os amigos em torno das grandes mesas, às vezes com 3 metros de comprimento, mesas algo rústicas, mas sólidas. [...] Quanto ao menu este brilha pela quantidade: tutu de feijão com lingüiça, leitão assado, pernil de porco assado, goiabada com queijo, cobu de fubá, e mais uma infinidade de pratos, todos tendo por sinal comum o serem maciços e fortes (TORRES, 1980, p. 496).
}

Entretanto, o olhar dos viajantes para a Minas daquele período diagnosticava o espaço da cozinha com condições precárias de higiene, tanto na casa dos ricos quanto na dos pobres. Ainda assim, muitas dessas tradições da comida mineira viriam compor futuramente o cenário turístico das cidades tidas como históricas, e seus pratos típicos tornaram-se fator de hospitalidade para os futuros viajantes.

Nessa perspectiva, os viajantes estrangeiros, ao seu modo e chocados com os novos hábitos, forneceram depoimentos acerca dos costumes à mesa do mineiro. Relatam que a organização dos alimentos à mesa não fazia parte da preocupação dos mineiros. Mawe (1978, p. 138) afirma que os mineiros "colocam tudo amontoado na mesa e aí põem também um prato de feijão cozido; cada um serve à vontade, há apenas 
uma faca, da qual não fazem uso". Apesar disso, nesse mesmo trecho o viajante diz que "a farinha de milho, alimento principal, me pareceu de tão paladar e tão nutritiva que tive a curiosidade de conhecer seu preparo". Nota-se que esse tipo de visão paradoxal da alimentação já preconizava um ato de acolher que, embora distinto para os viajantes, passou a ser registrado como prática da hospitalidade mineira.

Entre as diversas análises sobre essa temática, situa-se Magalhães (2009, p. 139) quando conclui que "as dádivas feitas na forma de comida possuíam um papel de grande importância para obtenção de prestígio, servindo também para uma ostentação de riqueza. Riqueza que, verdadeira ou falsa, muitas vezes exibia no aparato da chamada 'mesa mineira"'. Em sentido dialógico do tempo, comparamos que os viajantes apontavam como "comida dos escravos" o que constitui hoje, no ramo turístico, a comida mineira típica: feijão, angu e couve.

Outro caráter analisado pelos viajantes, em Minas, foram as festas as quais serviam como uma espécie de "desforra" para compensar os poucos dias de abundância de modo que essa prática somente era possível para as pessoas mais abastadas. Tal fato demonstra que a confraternização, tradicionalmente vinculada aos mineiros, era possível somente a um determinado segmento e em contextos sociais específicos. Já no meio rural, constituído por grandes fazendas produtivas, as acolhidas eram generosas e a função simbólica e social dos alimentos era considerada superior ao seu valor nutritivo.

Lembremo-nos de Mauss (2008, p. 200) quando afirma que "podemos e devemos voltar ao arcaico, reencontrar motivos da vida e da acção conhecidos ainda por sociedades e classes numerosas; a alegria de dar em público; o prazer da despesa artística generosa, o prazer da hospitalidade e da festa privada e pública”.

As festas dos mineiros eram os festejos públicos, no meio das praças com sentido burguês, e as festas particulares no seio da família patriarcal com sentido moral. A vida familiar mineira no século XIX era mais citadina com uma melhor posição da mulher na sociedade. Outros fatos históricos ocorreram naquele período, tais como: transformação dos mestiços em classe média urbana e o lirismo nas relações amorosas, paradoxalmente, em um sistema escravocrata em que muitos mestiços se libertaram dos senhores.

Nesse retrospecto, é importante lembrar que o processo de diversificação social nas Minas foi, também, condicionado pelas flutuações da economia mineratória cujo povoamento possibilitou grande afluxo de mercadores à região: fixos (vendeiros, lojistas e taberneiros) e não fixos (tropeiros, mascates e boiadeiros). De acordo com Magalhães (2004), naquele período, as mulheres negras exerciam papel nas atividades comerciais de suma importância, tais como: cozinheiras, doceiras e fiandeiras, além de se destacarem no comércio como vendedoras, apesar de essa prática ser combatida pelo governo, sendo punidas com confiscos, prisões, fianças e açoites em praça pública. Com o tempo, as mulheres em Minas Gerais, normalmente forras ou escravas, passam a ter um considerável controle das vendas, o que demonstra sua amplitude na participação social no período.

Tem-se nisso que muitas famílias mineiras do século XIX, inclusive em Vila Rica, foram chefiadas por mulheres. Ao historicizar essa questão, Luciano Figueiredo (1995, p. 140) relaciona que "se para a Igreja a atuação feminina em determinadas funções domésticas parecia ultrapassar os limites desejáveis da moral cristã, é necessário situar a importância da associação entre o trabalho feminino e a economia doméstica". Tal associação ficava ainda mais evidente quando o ambiente doméstico era vinculado a um pequeno comércio, pois a mulher dividia os papéis com os parceiros administrando vendas e o domicílio. O mesmo autor conclui que a família popular mineira traduzia-se, no espaço, por excelência em solidariedade e, 
mesmo que intitulada por indisciplinada e promíscua, estabeleceu padrões de um cotidiano coletivo em que os afetos eram exagerados e onde, sob difíceis condições de vida, a prostituição pôde conviver ao lado da estrutura familiar. Tal estudo histórico se opõe à ideia da Tradicional Família Mineira como exemplo de papéis conservadores e modelo patriarcal.

$\mathrm{Na}$ contramão desse processo, os viajantes estrangeiros apenas se referiam à mulher "branca", a senhora de escravos que os hospedava, como sendo a brasileira; negando, assim, à negra e à mulata alguma visibilidade. No entanto, os relatos revelam muito mais sobre o pensamento quanto ao gênero daquele período, inclusive seus preconceitos em relação à condição feminina. Nas instâncias de trabalho doméstico (limpar, lavar, cuidar das crianças, costurar, bordar e servir de dama de companhia) e extradoméstico (agricultura, mineração e comércio ambulante) existiam mulheres escravas e não escravas, sempre de origem africana.

Os relatos tendenciosos, por serem escritos por homens, dizem respeito a uma classificação da mulher em que a branca seria para casar, mas não encarnava nem a sedução, nem a imagem do trabalho; a negra podia ser usada sexualmente, não servia para casar, mas apenas para o trabalho; a mulata servia como trabalhadora e até como amante, mas nunca como esposa. A exploração das negras e negros era utilizada no processo de acolhida dos viajantes naturalistas para demonstrar o poder dos senhores os quais prestigiava-os com dádivas diversas para a operacionalização da viagem, além da alimentação e hospedagens. Os políticos mineiros ainda concediam aos viajantes soldados para acompanhar durante a viagem, tratos dos animais e passaporte com amplas prerrogativas (FIGUEIREDO, 1995).

Situa-se, nesse caminho, Mauss (2008) quando diz que a "coisa dada" não é uma coisa inerte: a prestação total não somente obriga a retribuir os presentes recebidos, mas também supõe as obrigações de dar, por um lado, e a de receber, por outro. Surge daí a importância que o ser humano dá para as relações com o outro na representação de ser generoso, útil e importante. Diante disso, os sentimentos de gratidão emergem mesmo que inconscientemente. Assim, a troca de presentes na sociedade mineira daquele período resulta na produção da abundância de riquezas enquanto trocas voluntárias e obrigatórias de dádivas em uma lógica de poder.

Vê-se, desse modo, a ótica paradoxal dos viajantes referente às práticas de hospitalidade doméstica, comercial e pública nas Minas oitocentista, pois de um lado foi relatada a hostilidade das instalações das hospedarias e das práticas alimentares, por outro, foi exaltado o caráter hospitaleiro do povo mineiro no ato de acolher, e as "bondades" concedidas a eles nas fazendas e nas vilas. Saint-Hilaire (1975, p. 77) situa essa última característica na região de Mariana ao relatar que "ia percorrer uma região pacífica e hospitaleira". Ao se despedir de Vila Rica, Mawe (1978, p. 141) assevera sobre o caráter afetuoso da hospitalidade que lhe foi fornecida: "com tudo pronto para a minha partida, despedi-me dos vários habitantes, agradecendo-lhes suas gentilezas para comigo, e recebendo deles as maiores demonstrações de amizade e de boa viagem". O viajante conclui que "diante das péssimas estradas, hospedarias miseráveis, má comida e acomodações ainda piores, servia de exemplo ao adágio que 'com o coração alegre tudo está bem””.

\section{CONSIDERAÇÕES FINAIS}

Em Minas Gerais, no século XIX, os viajantes naturalistas gozavam de um prestígio social que possibilitavaos obter abrigo privilegiado nas fazendas de uma elite brasileira escravocrata. A hospitalidade doméstica 
mineira oitocentista era movida pela troca posta entre um anfitrião que buscava a importância social de receber o estrangeiro europeu e um hóspede que se utilizava de instalações domésticas mais adequadas ante as hospedarias. Essa relação foi situada em um regime de dádivas as quais se sobrepunham ao caráter puramente material, pois havia também um dado espírito afável na coisa trocada. Temos como exemplo o fato interesseiro no qual era honroso e motivo de prestígio acolher o viajante europeu e, ao mesmo tempo, era desinteresseiro no que tange à abertura dos laços sociais familiares domésticos sem dispêndio financeiro para tal. Tais atitudes eram dadivosas porque eram livres e obrigatórias, ao mesmo tempo, tal como nas sociedades antigas estudadas por Mauss (2008) em que havia um espírito da coisa dada.

Considera-se que a hospitalidade dos mineiros daquele período, na forma de servir grande quantidade de alimentos aos viajantes, funcionava como reforço da ideia de abundância e prosperidade. A fartura de víveres do meio rural possibilitava essa hospitalidade e, por vezes, até o esbanjamento, dando a ideia de recursos ilimitados. Apesar disso, entre os mineiros, essa abundância de gêneros servia também para esquecer as duras privações vivenciadas nos primeiros anos de povoamento do território. Essa precariedade vivida anteriormente foi simbolizada pela oferenda de dádivas exacerbada aos viajantes na forma de oferecer comida. Nessa perspectiva, Mauss (2008, p. 170) diz que "está na natureza do alimento ser partilhado; não o partilhar com outro é matar a sua essência, destruí-la para si e para os outros".

Essa relação é entendida como uma dádiva assimétrica, já que não havia necessariamente igualdade entre a coisa ofertada e a coisa retribuída. Tal fato, estritamente simbólico, expressa a assimetria das trocas realizadas pelos envolvidos no processo de acolhida e suas práticas de poder sobre o outro de forma ambígua, ou seja, livres e obrigatórias ao mesmo tempo. Entretanto, é importante ressalvar que as relações de hospitalidade e hostilidade foram descritas pelos viajantes europeus do século XIX à sua maneira e servindo a seus interesses. O poder das coisas dadas, expressas nos relatos da literatura de viagem, sempre permaneceu de forma paradoxal entre os anfitriões mineiros e os hóspedes viajantes estrangeiros, pois havia, por um lado, a abertura de suas casas e da exposição de suas relações familiares, e, por outro lado, existia uma questão introspectiva e desconfiada da personalidade dos habitantes das Minas.

Portanto, o regime das coisas trocadas na hospitalidade mineira oitocentista estabeleceu, em determinados espaços sociais e em um dado período do tempo, relações da tríade dar-receber-retribuir com as quais os agentes protagonistas, anfitriões e visitantes sentiram-se imbricados uns aos outros, de forma obrigatória e livre, em atos que simulam atitudes simbólicas de generosidade social com o outro, muito embora repletas de preconceitos por parte dos estrangeiros os quais se vinculavam às estruturas de poder do sistema escravocrata e patriarcal daquele período da história do Brasil. Destaca-se, por fim, que a hospitalidade aos viajantes estrangeiros era realizada a partir da hostilidade a outros grupos sociais, tais como os negros e as mulheres. A aparência afetiva dos anfitriões e as trocas com os estrangeiros não significavam apaziguamento social com os demais grupos.

Conclui-se que o olhar do viajante estrangeiro fez emergir representações e práticas paradoxais da hospitalidade mineira em uma narrativa eurocêntrica construída entre a ausência de racionalidade e o envolvimento afetivo. Apesar da alteridade no olhar para o outro, as relações foram permeadas com trocas assimétricas. A mitologia da mineiridade foi assim constituída pela oferta de dádivas no processo de acolhida ao outro em uma lógica de poder. 


\section{REFERÊNCIAS}

ARRUDA, M. A. N. Mitologia da mineiridade. 0 imaginário mineiro na vida política e cultural do Brasil. São Paulo: Brasiliense, 1990.

AUGUSTIN, G. Literatura de viagem na época de Dom João VI. Belo Horizonte: Editora UFMG, 2009.

BRUSADIN, L. B.; PANOSSO NETTO, A. La dádiva y el intercambio simbólico: supuestos sociológicos y filosóficos para la teoría de la hospitalidad en las sociedades antiguas y modernas. Estudios y Perspectivas en Turismo, v. 25, n. 4, 2016.

BUNBURY, C. J. F. Viagem de um naturalista inglês ao Rio de Janeiro e Minas Gerais: 1833.1835 . Belo Horizonte: Ed. Itatiaia, 1981.

BURTON, R. F. Viagem do Rio de Janeiro ao Morro Velho. Belo Horizonte: Ed. Itatiaia,1976.

CALDCLEUGH, A. Travels in South America during the years 1819-20-21: containing an account of the present state of Brazil, Buenos Aires and Chile. London: John Murray, 1825.

CAMARGO, L. O. de L. Hospitalidade. São Paulo: Aleph, 2004.

DERRIDA, J. Adeus a Emmanuel Lévinas. São Paulo: Perspectiva, 2004.

FIGUEIREDO, L. R. A. Barrocas famílias. Vida familiar em Minas Gerais no século XVIII. São Paulo: Hucitec, 1995.

GODBOUT, J. T. 0 espírito da dádiva. Rio de Janeiro: Editora Fundação Getúlio Vargas,1999.

GOTMAN, A. O comércio da hospitalidade é possível? Revista Hospitalidade, São Paulo, v. VI, n. 2, jun./dez. 2009.

HOLANDA, S. B. Raízes do Brasil. São Paulo: Companhia das Letras, 1995.

LASHLEY, C. Hospitalidade e Hospitabilidade. Revista Hospitalidade. São Paulo, v. XVII, noo especial, mai. 2015.

LEITE, I. B. Antropologia da viagem: escravos e libertos em Minas Gerais do século XIX. Belo Horizonte: Editora UFMG, 1996.

LÉVI-STRAUSS, C. Tristes Trópicos. Barcelona: Ediciones Paidós Ibérica, 1988.

MAGALHÃES, S. M. A mesa de Mariana: produção e consumo de alimentos em Minas Gerais (17511850). São Paulo: Annablume; Fapesp, 2004.

MAUSS, M. Ensaio sobre a dádiva. Lisboa: Edições 70, 2008.

MAWE, J. Viagens ao interior do Brasil. Belo Horizonte: Ed. Itatiaia, 1978.

POHL, J. E. Viagem ao interior do Brasil. Belo Horizonte: Ed. Itatiaia, 1976.

SAINT-HILAIRE, A. Viagem pelas províncias do Rio de Janeiro e Minas Gerais. Belo Horizonte: Ed. Itatiaia, 1975.

SPIX, J. V. Viagem pelo Brasil: 1817-1820 / Spix e Martius. Belo Horizonte: Ed. Itatiaia, 1981.

TORRES, J. C. O. História de Minas Gerais. Belo Horizonte: Lemi, 1980.

WELLS. J. W. Three thousand Miles through Brazil from Rio de Janeiro to Maranhão. London: [s.n.], 1886. 